\title{
Lung function in infants with cystic fibrosis
}

\author{
CAROLINE S BEARDSMORE, EPHRAIM BAR-YISHAY, CHANNAH MAAYAN, \\ YAACOV YAHAV, DANIEL KATZNELSON, SIMON GODFREY
}

From the Pulmonary Function Laboratory and Department of Pediatrics, Hadassah University Hospital, Mount Scopus, Jerusalem; and the Department of Pediatrics, Chaim Sheba Medical Center, Tel Hashomer, Israel

ABSTRACT Lung function was measured in 28 infants with cystic fibrosis and repeated in 17 of the infants during the first year of life. Thoracic gas volume (TGV) and specific airway conductance (sGaw) were measured plethysmographically and maximum forced expiratory flow at functional residual capacity ( $\dot{\mathrm{V}}$ maxFRC) was derived from the partial expiratory flow-volume curve. At the time of the initial evaluation respiratory function was correlated with the clinical condition of the infants but not with age. There was a good correlation between sGaw and $\dot{V}$ maxFRC when both were expressed as percentages of the predicted normal values. On the basis of the normal range for sGaw the infants were divided into two groups. Group $A(n=9)$, who had normal sGaw, were younger and had a lower clinical score and normal VmaxFRC and TGV values. Group B $(n=19)$, who had low sGaw, had increased TGV and decreased VmaxFRC. There was no correlation with age for any measure of lung function for the population as a whole. Repeat testing was undertaken at intervals in 17 representative infants. In most of these infants the relation between sGaw and VmaxFRC was maintained; there was no evidence that $\dot{V} \operatorname{maxFRC}$ was affected before sGaw. There was no functional evidence that the earliest changes in cystic fibrosis occur in small airways, as reflected by changes in VmaxFRC in infancy.

\section{Introduction}

Impairment of respiratory function is the major cause of mortality and morbidity in cystic fibrosis. ${ }^{12}$ During infancy, when the lung is growing and developing rapidly, lung damage would seem likely to be more harmful than later. Accurate assessment of respiratory function at this age is therefore important, so that changes brought about either by progression of the disease or by treatment can be identified.

Studies in older children have suggested that the earliest abnormalities in cystic fibrosis occur in small airways. For example, appreciable hypoxia has been noted at a stage when other indices' of lung function are normal, ${ }^{3}$ and there is a more rapid decline in maximum mid expiratory flow rate than in other indices of lung function. ${ }^{4}$

Studies using the infant whole body plethysmograph have found several instances in which airway resistance or its derivatives were normal in infants with cystic fibrosis, ${ }^{56}$ suggesting that the larger airways at least are basically healthy in early life. The important

Address for reprint requests: Professor S Godfrey, Department of Pediatrics, Hadassah University Hospital, Mount Scopus, POB 24035, Jerusalem 91240, Israel. questions, however, are whether the smaller airways are healthy and whether progression to abnormal function is inevitable in infancy.

We have developed a technique for obtaining partial forced expiratory flow-volume curves in infants, ${ }^{78}$ which closely resemble the forced expiratory flowvolume loops of older children and adults. To the extent that expiratory flow rates at low lung volumes may be an index of small airway function, the techniques now available for the investigation of infants should allow us to explore the origin and progression of airway disease in the early stages of cystic fibrosis.

\section{Methods}

\section{SUBJECTS}

In total 28 infants with cystic fibrosis were studied on 51 occasions, 17 on more than one occasion. The diagnosis of cystic fibrosis was confirmed in each case by a positive sweat test result. The age range of the infants was 5-57 weeks and their weight was 2.8-10.5 $\mathrm{kg}$ at the time of testing. All infants were regularly attending our cystic fibrosis clinics and receiving routine treatment, including continuous antibiotics and physiotherapy. The nature of the tests was explained to the parents, who gave their consent and 
Table 1 Clinical evaluation score used in the week before the test

0 Completely well

1 Episodic mild cough or dyspnoea, or both; normal radiograph or slight transient changes only

2 Mild but persistent cough and dyspnoea; mild but persistent radiographic changes

3 Moderate persistent cough and dyspnoea; persistent radiographic changes with parenchymal infiltrates

4 Severe persistent cough and dyspnoea with gross persistent radiographic changes

were present while they were being carried out. On the basis of clinical history and examination the physician in charge of the patient graded the respiratory state for the week before the tests on a scale from 0 (normal) to 4 (severely affected) according to the criteria in table 1 . No infant had evidence of an acute infective exacerbation at the time of the tests. After light sedation with chloral hydrate $(50-100 \mathrm{mg} / \mathrm{kg})$ the infants were placed in a whole body plethysmograph ${ }^{9}$ for measurement of specific airway conductance (sGaw) and partial forced expiratory flow-volume loops. ${ }^{8}$

\section{MEASUREMENT OF SPECIFIC AIR WAY}

\section{CONDUCTANCE}

Thoracic gas volume (TGV) and airways resistance (Raw) were measured with the infant whole body plethysmograph and rebreathing apparatus, ${ }^{9}$ recently developed computer techniques being used to facilitate calculations. ${ }^{10}$ The sleeping infant lay in the plethysmograph, breathing through a facemask and respiratory circuit, which included a screen pneumotachograph to measure flow and an outlet to measure mouth pressure $(\mathrm{Pm})$. The apparatus included two pneumatically operated valves to allow the infant to breathe either from the plethysmograph or from a rebreathing bag. Both valves could be closed to produce total airway occlusion.

TGV was measured according to the method of DuBois et al ${ }^{11}$ as modified for infants. ${ }^{12}$ The infant breathed room air quietly through the apparatus until both valves were closed for five or six seconds, during which time he made respiratory efforts against the occlusion. The resultant changes in plethysmograph pressure (Pbox) and Pm were then used to calculate TGV. The recorded signals (flow, Pm, and Pbox) were sampled directly by the computer (Digital PDP 11/23) for analysis, and after inspection and selection by the operator the results were calculated.

Raw was measured while the infant was breathing quietly through the apparatus. The infant breathed heated, humidified, oxygen enriched air from a $500 \mathrm{ml}$ rebreathing bag within the plethysmograph to prevent artefacts due to changes in temperature and humidity of the inspired and expired gas. The signals of flow $(\dot{V})$ and Pbox were sampled by the computer. The $\stackrel{\mathbb{N}}{.}$ operator selected representative breaths, from which $\vec{F}$ Raw and its reciprocal, conductance (Gaw), were $\stackrel{0}{?}$ calculated by conventional methods, ${ }^{1213}$ recently developed computer programs" being used. Gaw was $\frac{\bar{\sigma}}{\bar{\omega}}$ divided by actual TGV to give sGaw. Each value was $\underset{\nabla}{\vec{\sigma}}$ expressed as a percentage of the infant's predicted $\triangle$ normal value derived from the data of Stocks and $\%$ Godfrey'2 (from 103 normal infants studied during the $\overrightarrow{0}$ first year of life-J Stocks, personal communication). The within subject coefficient of variation from these $\vec{\omega}$ normal data is $3.7 \%$ for TGV and $5.9 \%$ for Raw. The intersubject coefficient of variation of TGV was $6.8 \% \times$ and that of sGaw $14 \%$. The normal range (mean and $\vec{\omega}$ two standard deviations) was therefore taken as $-v$ $86-114 \%$ predicted for TGV and $72-128 \%$ predicted or for sGaw.

MEASUREMENT OF PARTIAL FORCED EXPIRATORY $\vec{c}$ FLOW

Measurements of partial forced expiratory flow (PEFV), which were generally made immediately $\vec{\oplus}$ before those of sGaw, used apparatus and methods. described elsewhere. ${ }^{78}$ The infant lay within a double walled plastic jacket, itself within a canvas jacket that reached from the thoracic inlet to the pubis. The plastic jacket could be rapidly inflated (full pressure up to $50 \mathrm{~cm} \mathrm{H}_{2} \mathrm{O}$ within $100 \mathrm{~ms}$ ) to provide a firm but gentle squeeze around the chest and abdomen as the $\overrightarrow{\vec{B}}$ canvas jacket restricted outward expansion of the $\frac{0}{3}$ plastic jacket during inflation. The infant breathed through a facemask and pneumotachograph to produce a flow signal, which was sampled by the computer and integrated to produce a flow-volume음 loop on the display. At least 10 quiet breaths were observed, to ensure that the pattern of breathing was stable. A series of inflations was performed with different inflation pressures at end inspiration and the $ᄋ$ resulting PEFV loop was inspected. If this was acceptable, the computer calculated the maximum음 expiratory flow rate at the resting lung volume for the $D$ preceding breath (V́maxFRC). Applied pressure was을. increased until a maximum value was obtained, $\overline{\mathrm{N}}$ beyond which an increase in pressure caused no $\sigma$ further increases in $\dot{V} \max F \mathrm{RC}$ values or even a $\mathrm{O}$ decrease. The $\dot{V}$ maxFRC value reported is the highest $\tilde{\omega}$ value obtained with at least one more value withing $10 \%$ of it. The measurement of $\dot{V} \operatorname{maxFRC}$ wase standardised by expressing it in terms of actual TGV $\frac{\text { Tे }}{\mathscr{C}}$ per second.

In our original study of $\dot{V} \operatorname{maxFRC}$ in 11 healthy $T$ newborn infants aged 1-9 days ${ }^{7}$ mean $\dot{V}$ max FRC was $\bar{O}$ 1.9 TGV/s and the mean intrasubject and intersubject $\stackrel{\mathbb{D}}{\Omega}$ coefficients of variation were $9.5 \%$ and $30.5 \%$. The $\frac{\mathbb{Q}}{Q}$ present study, however, was performed on older $\sigma$ infants. The data collected by Taussig et al ${ }^{7}$ suggested 
that the values for infants were similar, when expressed as TGV/s, to those in 3-6 year old children, ${ }^{14}$ and we have recently shown ${ }^{15}$ VmaxFRC to be even higher in older children than originally reported for infants. ${ }^{7}$ When the results of all studies on the 16 children under 3 years of age are combined the new mean value for all infants is $2 \cdot 11$ (SD 0.57) TGV/s. All values of $\dot{V} \max F R C$ were expressed as percentages of $2.11 \mathrm{TGV} / \mathrm{s}$ and the normal range was taken as $46-154 \%$ (predicted mean and 2 SD).

Correlations were tested by means of best fit lines by the least square method. Statistical comparisons between the two groups were performed with the unpaired $t$ test and by the $\chi^{2}$ test as appropriate. Differences were regarded as significant when $p<$ 0.05 .

\section{Results}

Lung function was measured in 28 infants, 17 of whom were studied on two or more occasions, during the first year of life.
INITIAL VALUES

The results of the first lung function test on each infant and relevant clinical data are given in table 2 . The infants were divided into two groups according to whether sGaw was within the normal range. Group A (nine infants) had normal values on average for TGV and VmaxFRC as well as for sGaw. Group B (19 infants) had on average a value for TGV at the upper limit of normal but VmaxFRC as well as sGaw was below normal. Group A infants were significantly younger $(p<0.01)$ than group $B$ and also lighter $(p$ $<0.01)$ and shorter $(p<0.01)$. Group B infants had a mean clinical score three and a half times greater than group A ( $<<0.01)$, their sGaw was less (by definition), their VmaxFRC was lower ( $<<0.005)$, and their TGV was higher (though this difference was not significant). In all but one of the nine infants in group $A$ both sGaw and $\mathrm{V} \max F R C$ were within the normal range, but in group B (chosen because of low sGaw) seven of the 19 infants had values for VmaxFRC within the normal range.

There was no correlation between age and either

Table 2 Clinical details and initial lung function of the two groups

\begin{tabular}{|c|c|c|c|c|c|c|c|}
\hline $\begin{array}{l}\text { Patient } \\
\text { No }\end{array}$ & $\begin{array}{l}\text { Age } \\
\text { (weeks) }\end{array}$ & $\begin{array}{l}\text { Weight } \\
(\mathbf{k g})\end{array}$ & $\begin{array}{l}\text { Length } \\
(\mathrm{cm})\end{array}$ & $\begin{array}{l}\text { Clinical } \\
\text { state }\end{array}$ & $\begin{array}{l}T G V \\
\text { (\% pred) }\end{array}$ & $\begin{array}{l}\text { sGaw } \\
\text { (\% pred) }\end{array}$ & $\begin{array}{l}\dot{V} \max F R C \\
(\% \text { pred })\end{array}$ \\
\hline \multicolumn{8}{|l|}{ GROUP A } \\
\hline 1 & 6 & $2 \cdot 8$ & 49 & 0 & 87 & 113 & 167 \\
\hline 2 & 13 & $2 \cdot 8$ & 49 & 0 & 90 & 116 & 153 \\
\hline 3 & 14 & $4 \cdot 4$ & 57 & 0 & 70 & 104 & 116 \\
\hline 4 & 18 & $5 \cdot 5$ & 64 & 1 & 116 & 98 & 79 \\
\hline 5 & 5 & $3 \cdot 3$ & 51 & 0 & 81 & 113 & 55 \\
\hline 6 & 12 & 2.9 & 50 & 0 & 113 & 107 & 75 \\
\hline 7 & 13 & $2 \cdot 8$ & 46 & 0 & 112 & 89 & 42 \\
\hline 8 & 8 & 4.4 & 52 & 3 & 103 & 86 & 77 \\
\hline 9 & 22 & $5 \cdot 8$ & 62 & 1 & 67 & 84 & 64 \\
\hline Mean (SEM) & $12(2)$ & $3.9(0.4)$ & $53(2)$ & $0.56(0.03)$ & $93(6)$ & $101(4)$ & $92(16)$ \\
\hline \multicolumn{8}{|l|}{ GROUP B } \\
\hline 10 & 31 & $6 \cdot 8$ & 68 & 1 & 81 & 43 & 86 \\
\hline 11 & 24 & 4.9 & 64 & 1 & 141 & 67 & 64 \\
\hline 12 & 29 & $7 \cdot 5$ & 71 & 1 & 106 & 39 & 48 \\
\hline 13 & 47 & $10 \cdot 5$ & 75 & 0 & 79 & 38 & 43 \\
\hline 14 & 10 & 3.8 & 55 & 1 & 129 & 32 & 76 \\
\hline 15 & 8 & $4 \cdot 1$ & 55 & 4 & 94 & 58 & 41 \\
\hline 16 & 32 & $7 \cdot 0$ & 70 & 1 & 88 & 43 & 36 \\
\hline 17 & 31 & $7 \cdot 0$ & 68 & 3 & 104 & 39 & 14 \\
\hline 18 & 8 & $4 \cdot 7$ & 55 & 2 & 70 & 38 & 14 \\
\hline 19 & 17 & 3.7 & 51 & 3 & 215 & 22 & 14 \\
\hline 20 & 24 & $6 \cdot 7$ & 65 & 1 & 85 & 60 & 73 \\
\hline 21 & 36 & $7 \cdot 1$ & 68 & 2 & 91 & 40 & 85 \\
\hline $\begin{array}{l}22 \\
23\end{array}$ & 28 & $6 \cdot 8$ & 69 & 2 & 98 & 36 & 25 \\
\hline $\begin{array}{l}23 \\
24\end{array}$ & $\begin{array}{l}32 \\
30\end{array}$ & $\begin{array}{l}7 \cdot 9 \\
6.5\end{array}$ & $\begin{array}{l}73 \\
66\end{array}$ & $\begin{array}{l}3 \\
3\end{array}$ & 104 & 38 & 25 \\
\hline 25 & 14 & $3 \cdot 1$ & $\begin{array}{l}00 \\
50\end{array}$ & $\begin{array}{l}3 \\
1\end{array}$ & $\begin{array}{l}110 \\
122\end{array}$ & $\begin{array}{l}39 \\
28\end{array}$ & $\begin{array}{l}82 \\
17\end{array}$ \\
\hline 26 & 11 & 3.6 & 52 & 1 & 141 & 28 & 22 \\
\hline 27 & 19 & $3 \cdot 7$ & 53 & 3 & 164 & 56 & 43 \\
\hline 28 & 44 & $6 \cdot 6$ & 69 & 4 & 157 & 37 & 33 \\
\hline Mean (SEM) & $25(3)$ & $5.9(0.4)$ & $64(2)$ & $1.95(0.03)$ & $115(8)$ & $41(3)$ & $44(6)$ \\
\hline
\end{tabular}

TGV, total gas volume; sGaw, specific airway conductance; V́maxFRC, maximum forced expiratory flow at functional residual capacity. 
Table 3 Correlations

\begin{tabular}{|c|c|c|c|}
\hline $\begin{array}{l}\text { First } \\
\text { measurement }\end{array}$ & $\begin{array}{l}\text { Second } \\
\text { measurement* }\end{array}$ & $r$ & $p$ \\
\hline \multicolumn{4}{|c|}{ Initial tests on whole group $(n=28)$} \\
\hline $\begin{array}{l}\text { Clinical score } \\
\text { TGV } \\
\text { sGaw } \\
\text { VmaxFRC\% } \\
\text { sGaw }\end{array}$ & $\begin{array}{l}\text { Age } \\
\text { Clinical score } \\
\text { Clinical score } \\
\text { Clinical score } \\
\text { V́maxFRC \% }\end{array}$ & $\begin{array}{r}0.245 \\
0.411 \\
-0.527 \\
-0.432 \\
0.659\end{array}$ & $\begin{array}{l}\text { NS } \\
<0.05 \\
<0.005 \\
<0.025 \\
<0.001\end{array}$ \\
\hline \multicolumn{4}{|c|}{ Initial tests on retest group $(n=17)$} \\
\hline $\begin{array}{l}\text { TGV } \\
\text { sGaw } \\
\text { VmaxFRC\% } \\
\text { sGaw }\end{array}$ & $\begin{array}{l}\text { Clinical score } \\
\text { Clinical score } \\
\text { Clinical score } \\
\text { VmaxFRC \% }\end{array}$ & $\begin{array}{r}0.576 \\
-0.402 \\
-0.595 \\
0.709\end{array}$ & $\begin{array}{l}<0.025 \\
\text { NS } \\
<0.025 \\
<0.005\end{array}$ \\
\hline \multicolumn{4}{|c|}{ Final tests on retest group $(n=17)$} \\
\hline $\begin{array}{l}\text { TGV } \\
\text { sGaw } \\
\text { VmaxFRC\% } \\
\text { sGaw }\end{array}$ & $\begin{array}{l}\text { Clinical score } \\
\text { Clinical score } \\
\text { Clinical score } \\
\text { V́maxFRC \% }\end{array}$ & $\begin{array}{r}0.702 \\
-0.331 \\
-0.376 \\
0.496\end{array}$ & $\begin{array}{l}<0.005 \\
\text { NS } \\
\text { NS } \\
<0.05\end{array}$ \\
\hline
\end{tabular}

*\% means percentage of the predicted value throughout. Abbreviations as in table 2.

clinical state or measures of airways obstruction in the initial investigation on the 28 infants. There were significant correlations between all indices of lung function and clinical score, the best correlation being for sGaw (table 3). There was also a significant correlation between sGaw and VmaxFRC when both were expressed as percentages of predicted values (fig 1 and table 3).

RESPIRATORY FUNCTION AT FOLLOW UP

Results of clinical evaluation and lung function tests in the 17 infants who were retested are given in table 4 and figure 2. At the time of their initial test the mean

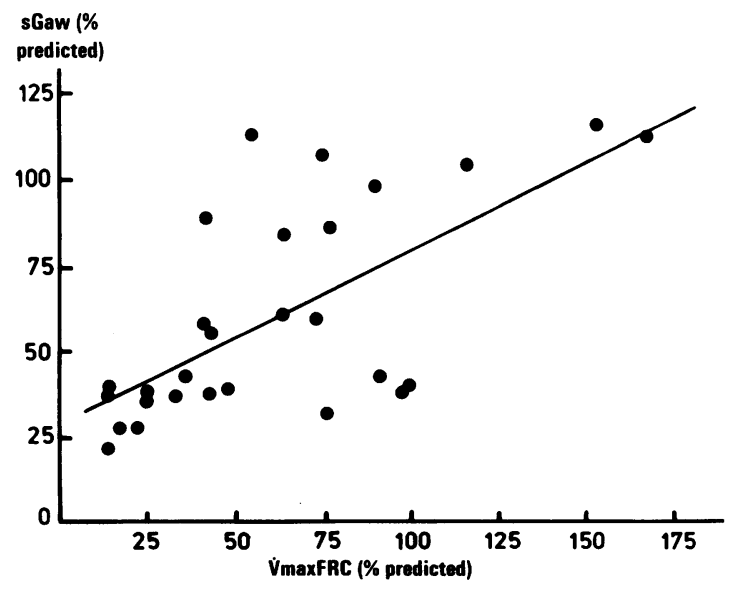

Fig 1 Specific airway conductance (sGaw, \% predicted) plotted against maximum expiratory flow at FRC

( $\dot{\text { max }}$ FRC, \% predicted) for all infants at the time of the first test. The regression line is shown $(r=0.66)$.
(SEM) age was $19.5(2.5)$ weeks and clinical score $1.4 \stackrel{\bigotimes}{.}$ $(0 \cdot 3)$. Neither these values nor any of the indices of $\vec{F}$ lung function in these 17 infants differed significantly from those of the remaining 11 infants and they are thus considered to be representative of the whole group. At the time of their final tests the 17 infants $\vec{\nabla}$ were on average just over twice as old (42.8 (2.1) weeks) but their clinical scores remained virtually is unchanged. The mean TGV (\% pred) had fallen $\overrightarrow{0}$ slightly, from 117 (9) to within the normal range (111. (10)); but the difference did not reach significance. $\vec{\omega}$ sGaw values (\%) had fallen from $68(8)$ to $53(6)$ (NS) and VंmaxFRC (\%) had fallen from 74 (11) to $55(8)$ : $\mathrm{p} \overrightarrow{\times}$ $<0.025$. With the presence or absence of values for $\vec{\omega}$ sGaw and VmaxFRC within the normal range as an index, five of the 17 infants had improved during of follow up, four were the same, and eight had deteriorated. Six of the 17 infants had had values for sGaw and VmaxFRC within the normal range initially $\vec{c}$ (Nos 1-4, 6, and 8) and only two of these (Nos 3 and 8) remained normal at follow up. On the other hand, two infants with initially abnormal function (Nos 10 and

Table 4 Results of repeat tests in 17 infants

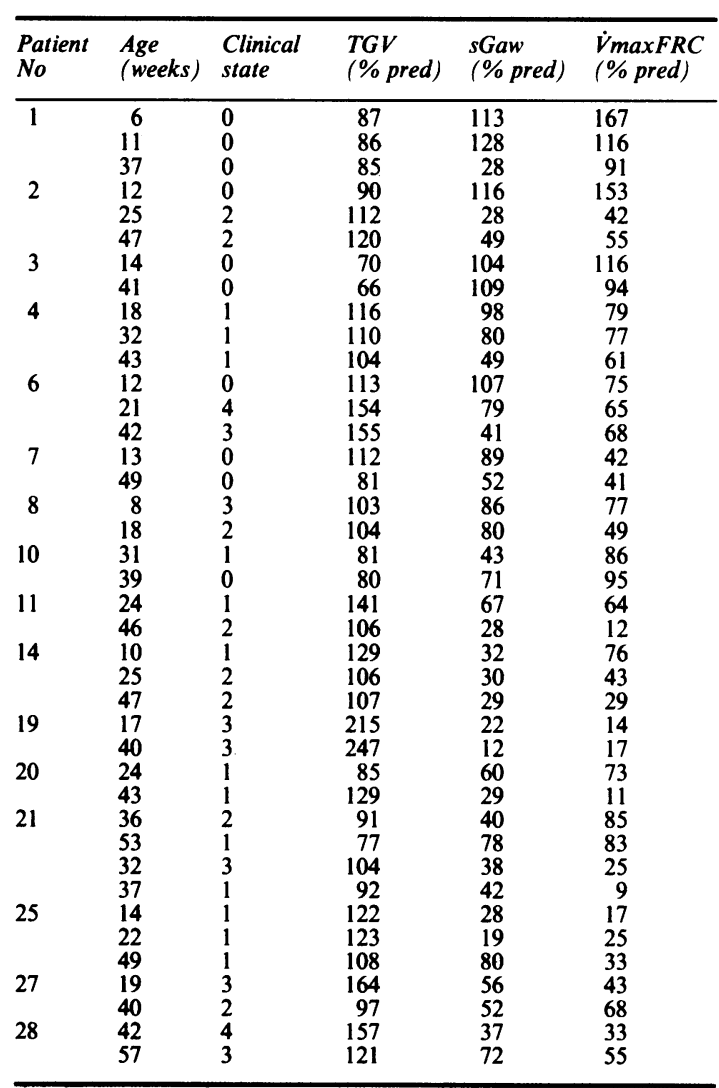

Abbreviations as in table 2. 


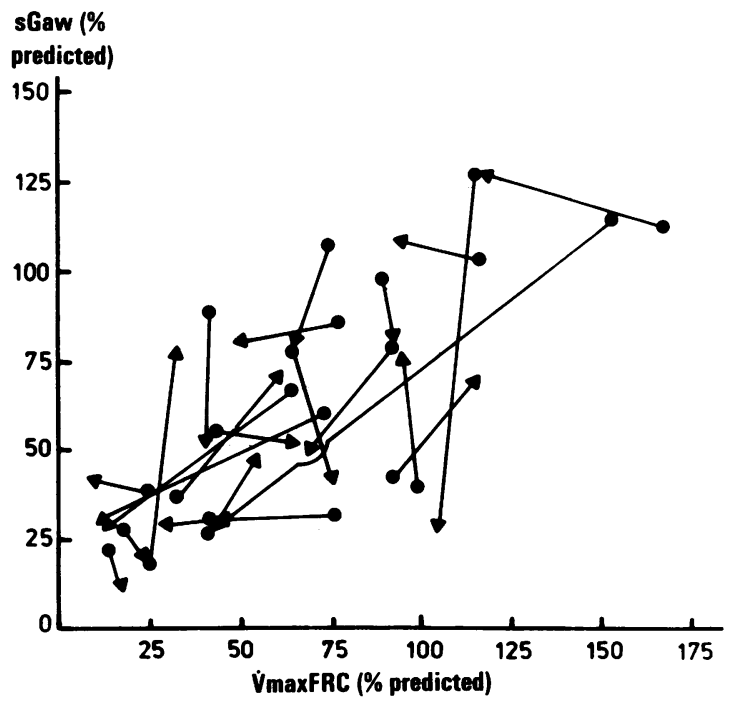

Fig 2 Specific airway conductance (sGaw, \% predicted) plotted against $\dot{V}$ maxFRC (\% predicted) for the 14 infants studied on more than one occasion. The initial tests are indicated by circles and the intermediate and final studies by arrow heads.

21) were within the normal range on follow up.

The correlations between the various tests and the clinical score for the 17 infants at the time of their initial and final examinations are given in table 3. At the time of the initial test the pattern was similar to that for all 28 infants but the correlation between sGaw and clinical score failed to reach significance. At the time of the final examination TGV was correlated significantly with the clinical score. The relation between sGaw and VmaxFRC for the 17 infants was similar to that for the whole group at the time of both their initial and their final examinations. In most of the infants retested the general direction of change in sGaw and VmaxFRC followed the regression line for their initial value (figs 1 and 2) but some infants showed more change in one index than in the other. There was no evidence that any one measure of lung function was more sensitive to earlier changes than any other.

Of the five initially symptom free infants who were retested, four had normal lung function but three of the four had deteriorated during the follow up. Two of those who had had symptoms initially had normal function, one had deteriorated, and one remained normal. Of the 10 infants initially with symptoms two remained the same, three got worse, but five improved and two of these achieved normal lung function. By the end of the follow up period only four of the 17 infants had completely normal function, of whom two had been abnormal initially.

\section{Discussion}

This study has confirmed that infants with cystic fibrosis may have normal or virtually normal lung function. The finding that nine of the 28 infants had normal values for sGaw at the time of the initial test is in agreement with the results of previous studies. ${ }^{56}$

The ability to obtain forced expiratory flow-volume curves in infants is a recent development, although various indices derived from the flow-volume loop have long been used to assess airway function in older children and adults. ${ }^{3416}$ Measurements of forced expiratory flows in older patients with cystic fibrosis have suggested that reduction of maximal flow at low lung volume is the earliest indicator of abnormal function. ${ }^{47}$ It is of interest therefore that 15 of our 28 infants had values for VmaxFRC within the normal range at the time of their initial test. We have to consider whether our values for VmaxFRC were unduly high, as Loughlin et al ${ }^{18}$ have found that older patients with cystic fibrosis performing partial forced expiratory manoeuvres have supramaximal transient flows whose magnitude correlates with the state of disease. As we were careful not to use data from flowvolume curves in which peak flow occurred at or near functional residual capacity we do not believe this phenomenon to be important. Moreover, these infants with high values were the most healthy and therefore least likely to have large flow transients. ${ }^{18}$

The problem of predicting normal values for VंmaxFRC has already been considered. Tepper et al ${ }^{19}$ confirmed recently that VmaxFRC values in the newborn are higher than originally reported. They also showed, however, that VmaxFRC soon falls to a mean value of 1.19 (SD 0.59) $\mathrm{TGV} / \mathrm{s}$ and remains fairly constant with somatic growth over the first 15 months of life. Although we agree that $\dot{V}$ maxFRC is higher at birth and falls off gradually, ${ }^{15}$ we are not convinced that his lower values in later infancy are not a function of the technique used to apply the squeeze, as these values are even lower than those reported for older children ${ }^{14}$ and young adults. ${ }^{20}$ Until this issue is resolved by formal comparative studies, we think it best to continue to use the normal range obtained in our own laboratory. Had we used the values reported by Tepper et al ${ }^{19}$ our results would have approximately doubled but the directions of changes and the implications of the results would have been the same. This is true even when VmaxFRC is normalised on the basis of length rather than measured TGV.

Follow up studies of lung function over the early years in cystic fibrosis have shown a disappointing tendency to deterioration. ${ }^{4}$ On the other hand, in a study of 18 infants Phelan et al $^{6}$ found that treatment could restore lung function to normal even in those who had symptoms at the time of the initial study. If 
we take the normal range of specific pulmonary conductance (SGp) as the mean and 2 SD, only one of nine symptom free infants in their study had a value below normal initially, but this infant and one other had abnormally low values by the end of the follow up at an age similar to that of the infants in the present study. Of considerable interest was their finding that while seven of the nine infants with symptoms had SGp values below normal initially, all were within the normal range by the end of the follow up, albeit on the low side of normal. Our results differ somewhat from their encouraging findings. Four of the five symptom free infants we followed up had normal lung function initially and three deteriorated during follow up. Two of the 12 infants with symptoms had normal function initially, of whom one deteriorated and one remained normal. Of the remaining 10 infants with symptoms, two remained the same, three got worse but five improved, two of whom achieved normal lung function (table 4). Thus by the end of the follow up only four of the 17 infants had completely normal function. As our treatment was essentially the same as that of Phelan et $a l^{6}$ we cannot explain the difference, unless our patients were more severely affected when first tested or our tests were more sensitive in detecting abnormalities. It is also possible that sGaw and SGp do not reflect the functional changes in cystic fibrosis to the same extent.

Recent discussion on the nature of the factors responsible for expiratory flow limitation at low lung volume has been lucidly summarised by Mead. ${ }^{21}$ Both the equal pressure point theory ${ }^{22}$ and the wave speed theory ${ }^{23}$ suggest that the actual site of flow limitation lies in larger airways at high lung volume and probably migrates peripherally at low lung volume. The critical question, however, is which region of the lung is responsible for producing conditions that lead to a lowering of the maximum expiratory flow rates. In the simplest model, obstruction in the smallest airways leads to the fall of pressure needed to develop the conditions leading to flow limitation, but until recently there was no good evidence that such conditions actually occurred. Using a canine model of bronchiolitis obliterans, Mink et al ${ }^{24}$ provided convincing evidence that expiratory flow limitation reflected small airway disease in the presence of normal lung volume and total pulmonary resistance. Wright $e^{t} a l^{25}$ measured lung function in $\mathbf{9 6}$ patients who subsequently underwent lobectomy for localised disease, and were able to relate function to pathological condition. They showed that in patients with an FEV 1 greater than $80 \%$ predicted there was a correlation between the pathology of the small airways and the results of tests conventionally accepted as reflecting small airway function, including flow at low lung volume. In these patients the correlation with $\mathrm{FEV}_{1}$ was less good. In infants with airways obstruction ${ }^{26}$ we have shown $a^{*}$ good correlation between the time constant of the $\overrightarrow{\vec{F}}$ forced expiratory flow-volume curve and the mag- $-\frac{7}{0}$ nitude of flow-pressure looping during late expiration $\frac{\square}{0}$ in the infant whole body plethysmograph, which could $\frac{\bar{\omega}}{\overline{0}}$ be explained if both reflected small airway disease.

On the basis of measurements on necropsy material, $\frac{\Omega}{2}$ Hogg et al ${ }^{27}$ have suggested that small airways disease ${ }^{\infty}$ causes symptoms in infants because of the relatively $\vec{O}$ low conductance of peripheral airways. Unfortunately $\vec{\longrightarrow}$ they did not provide information about their normal ${ }_{\sigma}$ subjects, such as how and why they died. There were $\vec{F}$ apparently only two newborn infants, all the others $\times$ being 18 months or more; so their data may not be $\omega$ entirely representative of the normal pattern of growth $v$ of lung function. If flow limitation is a good index of $\mathrm{c}$ small airway function, as suggested by the studies mentioned earlier, then we see little evidence that small ${ }^{\circ}$ infants have poorer small airway function in life $\overrightarrow{\vec{C}}$ because their expiratory flow rates (corrected for lung volume) are if anything greater than in older children $\vec{\theta}$ and adults. ${ }^{7}$ Hogg et al also suggested that peripheral ${ }_{\infty}^{\circ}$ airway conductance was much more reduced than central airway conductance in children with cystic fibrosis. They studied, however, lungs from only three children with cystic fibrosis, aged from 4 to 7.5 years, who had died of pulmonary complications of the disease; so their findings are not necessarily applicable $\stackrel{\AA}{\complement}$ to the present study of living infants.

The arguments concerning the normal range of $\frac{0}{3}$ VmaxFRC in infancy would not apply to the initial tests in our patients as they were close in age to the normal subjects we have studied. Thus the finding of a normal VmaxFRC as well as sGaw in many of these음 infants, taken with the evidence cited above that small $\stackrel{\oplus}{\times}$ airways disease is reflected by flow limitation at low lung volume, suggests that small airways disease is not the earliest manifestation of cystic fibrosis.

This work was supported by the Cystic Fibrosis응 Foundation (USA) and the Joseph Levy Foundation $>$ (UK). CSB was in receipt of a travel award from the Wellcome Foundation (UK). SG holds the Smollerñ chair of pediatrics at Hadassah-Hebrew University.

\section{References}

Stern RC FP, Matthews LW. Course of cystic fibrosis in $95 \frac{1}{8}$ patients. J Pediatr 1976;89:406-11.

2 Wood RE, Boat TF, Doershuk CF. Cystic fibrosis. Am Rev Respir Dis 1976;113:833-78.

3 Lamarre A, Reilly BJ, Bryan C, Levison H. Early $\underset{\mathbb{D}}{\stackrel{O}{+}}$ detection of pulmonary function abnormalities in $\frac{\Omega}{\Phi}$ cystic fibrosis. Pediatrics 1972;50:291-8.

4 Corey M, Levison H, Crozier D. Five- to seven-yearo course of pulmonary function in cystic fibrosis. $\mathrm{Am} \operatorname{Rev}_{\Omega}$ 
Respir Dis 1976;114:1085-92.

5 Godfrey S, Mearns M, Howlett G. Serial lung function studies in cystic fibrosis in the first 5 years of life. Arch Dis Child 1978;53:83-5.

6 Phelan PD, Gracey M, Williams HE, Anderson CM. Ventilatory function in infants with cystic fibrosis. Arch Dis Child 1969;44:393-400.

7 Taussig LM, Landau L, Godfrey S, Arad I. Determinants of forced expiratory flows in newborn infants. J Appl Physiol 1982;53:1220-7.

8 Godfrey S, Bar-Yishay E, Arad I, Landau L, Taussig LM. Flow-volume curves in infants with lung disease. Pediatrics 1983;72:517-22.

9 Stocks J, Levy N, Godfrey S. A new apparatus for the accurate measurement of airway resistance in infancy. J Appl Physiol 1977;43:155-9.

10 Beardsmore CS, Godfrey S, Shani N, Maayan Ch, Bar-Yishay E. Airway resistance measurements throughout the respiratory cycle in infants. Respiration 1986;49:81-93.

11 DuBois AB, Botelho SY, Bedell GN, Marshall R, Comroe JH Jr. A rapid plethysmographic method for measuring thoracic gas volume. $J$ Clin Invest 1956;35:322-6.

12 Stocks J, Godfrey S. Specific airway conductance in relation to postconceptional age during infancy. J Appl Physiol 1977;43:144-54.

13 DuBois AB, Botelho SY, Comroe JH. A new method for measuring airway resistance in man using a body plethysmograph: values in normal subjects and in patients with respiratory disease. $J$ Clin Invest 1956;35:327-35.

14 Taussig LM. Maximal expiratory flows at functional residual capacity: a test of lung function for young children. Am Rev Respir Dis 1977;116:1031-8.

15 Shulman DL, Bar-Yishay E, Beardsmore CS, Beilin B, Godfrey S. Partial forced expired flow volume curves in young children during ketamine anesthesia. J Appl Physiol 1987;63:44-50.
16 Mellins RB, Levine OR, Ingram RH, Fishman AP. Obstructive disease of the airways in cystic fibrosis. Pediatrics 1968;41:560-73.

17 Mansell A, Dubrawsky C, Levison H, Bryan AC, Crozier DN. Lung elastic recoil in cystic fibrosis. $\mathrm{Am} \mathrm{Rev}$ Respir Dis 1974;109:190-7.

18 Loughlin GM, Cota KA, Taussig LM. The relationship between flow transients and bronchial lability in cystic fibrosis. Chest 1981;79:206-10.

19 Tepper RS, Morgan WJ, Cota K, Wright A, Taussig LM. Physiologic growth and development of the lung during the first year of life. Am Rev Respir Dis 1986;134:513-9.

20 Castile RG, Rodarte JR, Hyatt RE. Determinants of maximal expiratory flow and density dependence in normal humans. J Appl Physiol 1980;49:897-904.

21 Mead J. Expiratory flow limitation: a physiologists point of view. Fed Proc 1980;39:2771-5.

22 Pride NB, Permutt S, Riley RL, Bromberger-Barnea B. Determinants of maximal expiratory flow from the lungs. J Appl Physiol 1967;23:646-62.

23 Dawson SV, Elliott EA. Wave-speed limitation on expiratory flow-a unifying concept. J Appl Physiol 1977;43:498-515.

24 Mink SN, Coalson JJ, Whitley L, Greville H, Jadue C. Pulmonary function tests in the detection of small airway obstruction in a canine model of bronchiolitis obliterans. Am Rev Respir Dis 1984;130:1125-33.

25 Wright JL, Lawson LM, Paré PD, Kennedy S, Wiggs B, Hogg JC. The detection of small airways disease. Am Rev Respir Dis 1984;129:989-94.

26 Beardsmore CS, Maayan Ch, Bar-Yishay E, Godfrey S. Flow-pressure looping during plethysmography in wheezy infants. Pediatr Pulmonol 1985;1:27-31.

27 Hogg JC, Williams J, Richardson JB, Macklem PT, Thurlbeck WM. Age as a factor in the distribution of lower-airway conductance and the pathologic anatomy of obstructive lung disease. N Engl J Med 1970; 282:1283-7. 